Onuray Eğilmez, H. (2021). Müzik öğretmeni adaylarının iyi oluşları ile müzik performans kaygıları arasındaki ilişki. Uludağ Üniversitesi Fen-Edebiyat Fakültesi

Sosyal Bilimler Dergisi, 22(40), 499-525.

DOI: $10.21550 /$ sosbilder.735578

Araştırma Makalesi / Research Article

\title{
MÜZIKK ÖĞRETMENİ ADAYLARININ İYİ OLUŞLARI İLE MÜZİK PERFORMANS KAYGILARI ARASINDAKİ İLISSKİ
}

\author{
Hatice ONURAY EĞİLMEZ*
}

Gönderim Tarihi / Sending Date: 11 Mayıs / May 2020

Kabul Tarihi / Acceptance Date: 16 Temmuz / July 2020

ÖZET

Araştırma, müzik ögretmeni adaylarının iyi oluşlarının sahne performansları sırasında karşılaşabilecekleri kaygı düzeyine etkisini saptamak amacıyla yapılmıştır. Bu doğrultuda müzik öğretmeni adaylarının iyi oluş ve müzik performans kaygıları (MPK) incelenmiş, her iki durum arasındaki iliş̧ki ortaya konmuştur. Araştırmaya Bursa Uludă̆ Üniversitesi Eğitim Fakültesi Müzik Eğitimi Ana Bilim Dalında ĕgitim alan (kız $n=51$, erkek $n=35) 86$ ögrenci katılmıştır. Veriler Öğrenci Demografik Bilgi Formu, İyi Oluş Ölçeği (PERMA) ve Kenny Müzik Performans Kayglsl Envanteri (KMPKE) ile toplanmıştır. PERMA, KMPKE puanlarının cinsiyete göre ilişkisinin analizinde t-testi, PERMA ve KMPKE puanlarının öğrenim yıllarına göre ilişkisinin analizindeyse ANOVA kullanılmıştır. PERMA ve KMPKE puanlarl arasındaki ilişki ile PERMA arasındaki ilişkinin belirlenmesi içinse Pearson Korelasyon katsayısı hesaplanmıştır. Müzik öğretmeni adaylarının iyi oluş ve müzik performans kaygılarında cinsiyete, ögrenim yllına göre anlaml fark tespit edilemezken, PERMA genel puanı ve tüm alt boyutlart ile KMPKE puanları arasında negatif yönlü ve anlamlı ilişki bulunmuştur. Çalışma sonunda sorunun çözümüne ilişkin öneriler sunulmuştur.

Anahtar Kelimeler: iyi oluş, müzik, müzik ögretmeni adayları, performans kaygısı, performans

Doç. Dr., Bursa Uludağ Üniversitesi Eğitim Fakültesi Güzel Sanatlar Eğitimi Bölümü Müzik Eğitimi Ana Bilim Dalı, Bursa / TÜRKIYYE, hegilmez@uludag.edu.tr

Uludağ Üniversitesi Fen-Edebiyat Fakültesi Sosyal Bilimler Dergisi Uludağ University Faculty of Arts and Sciences Journal of Social Sciences

Cilt: 22 Sayı: 40 / Volume: 22 Issue: 40 


\title{
The Relationship between the Well-Being and Music Performance Anxiety of Pre-service Music Teachers
}

\begin{abstract}
The research was carried out to determine the effect of the well-being of pre-service music teachers on the level of anxiety they may encounter during the stage performances. For this purpose, the well-being and music performance anxieties (MPA) of the pre-service music teachers were examined, and the relationship between the two situations was revealed. A total of 86 students (girls $n=51$, boys $n=35$ ), educating in the Department of Music Education at Bursa Uludağ University Faculty of Education, participated in the study. Data were collected with Student Demographic Information Form, Perma Well-being Scale and Kenny Music Performance Anxiety Inventory (KMPAI). To analyze the relationship between PERMA and KMPAI scores by gender, t-test and to analyze the relationship between PERMA and KMPAI scores by education years, ANOVA was used. Pearson correlation coefficient was calculated to determine the relationship between PERMA and KMPAI scores. While there is no significant difference in the well-being and music performance anxiety of pre-service music teachers according to gender, and education year, a negative significant relationship was found between the PERMA general scores and all sub-dimensions scores with KMPKE. At the end of the investigation suggestions for the solution of the problem have been presented.
\end{abstract}

Key words: well-being, music, pre-service music teachers, performance anxiety, performance

\section{Giriş}

Performans sanatçılarının sahnede yaşadıkları ve zaman zaman sanatlarını icra etmelerini zorlaştıran "kaygı" bilimsel olarak ilk kez Freud tarafından incelenmiştir. Freud'a göre "kaygı", "kişiyi içeriden tehdit eden tehlikeye karşı gösterilen bir tepki” olarak tanımlanırken (Morgan, 1991, Baydağ \& Alpagut, 2016'dan) diğer bir tanımda kaygının kişinin dış veya iç dünyasından gelen bir uyaranla karşılaştığında yaşadığı, bedensel, duygusal ve zihinsel bir tepki olduğu, başka deyişle kişinin karşılaştığı durum ve olaylar karşısında 
duyduğu ve engellemekte zorluk çektiği aşırı endişe ve uyarılmışlık hali olduğu belirtilmektedir (Karakulak Özkan, 2020). Kaygının aslında, hayvanlar ve insanların karşılaştıkları tehlikelere karşı savunma mekanizması olduğu ve onların dış dünyada varlıklarını sürdürebilmeleri için gerekli bir dürtü olduğu bilinmektedir. Bu bakış açısıyla her canlıda olması gereken kaygı, tehdidin durumuna ve bireysel farklılıklara göre hafif tedirginlik şeklinde ortaya çıkabileceği gibi panik derecesinde de bireyleri etkileyebilmektedir (Köknel, 1982: 159). Kısacas1 kayg1 bireyi olumlu yönde motive edebileceği gibi, olumsuz olarak da etkileyebilmektedir. Bu noktada bireyin sahip olduğu kaygının düzeyi üzerinde durulması ve kaygı kontrol edilebilir bir noktadan uzaklaşmışsa bu durum ile baş edebilme yöntemlerinin uygulanması gerekmektedir. Alan yazınında "performans kaygısı" (Baydağ \& Alpagut, 2016; Baydă̆ \& Bolat Başoğlu, 2018; Kabakç1, 2016; Özgür, 2017), "performans anksiyetesi" (Gidergi Alptekin, 2012; Kafadar, 2009; Yağış̧an, 2009; Yöndem, 2012), "konser kaygısı" (Çimen, 2001), "sahne heyecanı" (Teztel \& Aşkın, 2007), "sahne korkusu" (Topoğlu, 2014) gibi çeşitli adlarla adlandırılan performans sırasında hissedilen söz konusu kaygının bazı icracıları mesleklerini bırakma noktasına getirdiği bilinmektedir (Fehm \& Schmidt, 2006: 99). Nagel (2010, Özgür, 2017'den) performans kaygısının nedenlerini sıralarken performans sırasında sanatçıları endişelendiren şeyin sahneden çok, performans sırasında ortaya çıkabilecek aksiliklerin, bunların yaratacağı aşağılanma duygusu ve hissedilecek utancın olduğunu belirtmektedir. Cemali (2017: vii) ise müzisyenler özelinde olan performans kaygısını doğuran nedenleri, kişilik özellikleri, kişinin sahip olduğu olumsuz bilişsel düşünce, fiziksel çevre özellikleri, olumsuz öğretmen, arkadaş ve aile tutumu, gelecek kaygısı gibi nedenleri sıralayarak genellemektedir. Kaygının ortaya çıkmasında etkili olan neden ne olursa olsun, yaşanan aşırı kaygının, iyi odaklanamamaktan oluşan dikkat dağınıklarına, sinirliliğe, bellek hatalarına, huzursuz bir duygu durumuna, bedensel gerginliğe ve

Uludağ Üniversitesi Fen-Edebiyat Fakültesi Sosyal Bilimler Dergisi Uludağ University Faculty of Arts and Sciences Journal of Social Sciences

Cilt: 22 Sayı: 40 / Volume: 22 Issue: 40 
sonuçta sahneye / konsere ç1kmaktan korkmaya neden olduğu belirtilmektedir (Kafadar, 2009: 13).

İyi bir müzikal performans için müzisyenin öncelikle kendini iyi hissetmesi, iyi olması gerekmektedir. $\mathrm{Bu}$ durum göz önünde bulundurulduğunda, iyi hissetmenin, "iyi oluşun” müzisyenlerin performans kaygılarıyla ilişkili olabileceği düşünülmektedir. Pozitif psikoloji alanının önemli kavramlarından biri olan "iyi oluş" insanın hayatındaki durumunu nasıl gördüğüyle ilgili bir kavramdır. "Öncelikle fiziksel iyi oluşu çağrıştırsa da 'iyi oluş', fiziksel, zihinsel ve ruhsal durumun tümünü kapsamakta, "bireyin bedensel, zihinsel ve ruhsal açıdan bir bütünlük içinde tam işlevde bulunarak iyi olma ve sağlıklılık halini yakalaması ve bu şekilde toplumsal ve doğal çevrede en verimli şekilde yaşamını sürdürmesi" (Myers vd., 2000: 252) olarak ifade edilmektedir.

Ryff (1989, Erdoğan, 2020'den) iyi oluş haline sahip olan bireylerin kendine karşı düşüncelerinin olumlu olduğunu, sağlam insan ilişkilerine sahip olduklarını, kendi kararlarını kendilerinin verebildiğini, kişisel gelişimlerine değer verdiklerini, yaşamın anlamının olduğuna inandıklarını ve zorluklarla başa çıkma becerilerinin yüksek olduğunu belirtmektedir.

Kendini iyi hisseden bireylerin daha mutlu olma eğiliminde oldukları, hayatlarına iyi bir şekilde yön vermek için daha motive oldukları bilinmektedir. İyi hisseden bireylerin iş yerinde daha iyi performans sergiledikleri, daha işbirlikçi oldukları, tatmin edici ilişkiler kurdukları, güçlü bağışıklık sistemine, daha iyi fiziksel sağlığa, öz düzenleme ve başa çıkma yeteneklerine sahip oldukları, daha uzun yaşadıkları, daha az uyku problemlerinin olduğu, tükenmişlik düzeylerinin düşük olduğu ve daha kontrollü oldukları tespit edilmiştir (Perma, 2020). 
İyi oluş kavramı ile ilgili yaklaşımlardan biri Seligman'ın kuramıdır. Mevcut araştırmada Seligman'ın (2011) kuramı ele alınmakta, söz konusu kuram göz önünde bulundurularak veri toplanmaktadır. Seligman'ın, farklı bileşenleri bir araya getirerek geliştirdiği çok boyutlu iyi oluş modelinde bireylerin mutluluğa erişebilmeleri için beş yol önerilmektedir. Seligman (2011, D'raven \& Pasha-Zaidi, 2016'dan) birinci yolun, keyifli yaşam için "olumlu duyguların" en üst düzeye çıkmasıyla, ikinci yolun zamanın nasıl geçtiğini anlamayacak kadar kendini bir etkinliğe kaptırmak olarak tanımlanabilecek "hayata bağlanmayla", üçüncü yolun hayatın amac1 ve anlamıyla ilgili, insana yaşamanın değerli ve yaşanmaya değer olduğu hissi veren "anlamlı yaşam" ile, dördüncü yolun başkaları tarafindan sevilmek ve değer görmeyle neticelenen "olumlu ilişkiler" ile ve beşinci yolun ise öz-yeterliği beraberinde getirdiğine inanılan "başarı" ile elde edilebileceğine vurgu yapmaktadır. Nitekim araştırmalar yüksek düzeyde iyi oluşa sahip olan bireylerin birçok özelliği arasında daha sosyal ve yaratıcı oldukları, stresle daha iyi başa çıktıkları belirtilmektedir (Eryılmaz \& Ercan, 2011: 140).

Araştırmalarla ortaya konan, iyi oluşu yüksek bireylerin sahip olduğu yaratıcılık ve stres ile daha iyi başa çıkma becerilerinin müzik performans kaygılarını olumlu yönde etkileyeceği düşünülmektedir. 4 yıllık lisans eğitimleri boyunca sınırlı sayıda sahne deneyimi yaşayan, jüri yönünde sınavlara tabii tutulan müzik öğretmeni adayları arasında da bazı öğrencilerin performans sırasında kaygı yaşadıkları gözlenmektedir. Araştırmada, müzisyenlerin kendilerini iyi hissetmelerinin performans sırasında karşılaşabilecekleri kayg1 düzeyine etkisinin olup olmadığına yönelik fikir vermesi açısından müzik öğretmeni adaylarının iyi oluş ile performans kaygıları incelenmesi ve her iki durum arasındaki ilişkinin ortaya konması amaçlanmıştır. 
Alan yazınında müzik performans kaygısının (MPK) nedenleri ve sonuçları üzerinde duran birçok araştırmaya rastlanmaktadır (Baydağ \& Alpagut, 2016; Brotons, 1994; Çimen, 2001; Dobos vd., 2019; Eğilmez vd., 2013; Gidergi Alptekin, 2012; Kenny \& Osborne, 2006; Kabakç1, 2016; Tamborrino, 2001; Teztel \& Aşkın, 2007; Topoğlu, 2014). Ayrıca müzik performans kaygısının bireyin benlik saygısı (Piji Küçük, 2010), öz yeterlik (Dempsey \& Comeau, 2019; Girgin, 2017; Jelen, 2010; Onuray Eğilmez, 2015; Topoğlu, 2014) gibi bireysel özellikler ile ilişkili olduğunu ortaya koyan araştırmalar da göze çarpmaktadır.

Alan yazınında performans kaygısının nedenleri ve kaygı ile baş edebilme yöntemlerini ele alan yukarıda sıralanan araştırmalar yer alırken iyi oluş ile performans kaygısı arasındaki ilişkiyi ortaya koyan araştırmalara yeterince rastlanmamıştır. Araştırma, müzisyenlerin iyi oluşlarının performans kaygılarına etkisine yönelik fikir vermesi açısından önemli görülmektedir. Ayrıca bu ilişkiyi ortaya koyan az sayıda araştırmadan biri olması bakımından araştırma önemini daha da artırmaktadır.

\section{Problem Durumu}

Mevcut araştırmada olumlu duygulara sahip olma, hayata bağlanma, yaşamın anlamına vararak hayatını sürdürme, olumlu ilişkilere sahip olma ve en önemlisi öz-yeterliği beraberinde getirdiğine inanılan başarılı olmanın performansa etkisinin olabileceğinden hareketle bireylerin iyi oluşlarının müzikal performanslarına olumlu etkisinin olabileceği düşünülmektedir. Bunun paralelinde iyi oluşun müzik performans kaygısı üzerinde bir etkisinin olup olmadığı merak konusu olmuştur. Bu görüşten hareketle araştırmada, müzik öğretmeni adaylarının iyi oluş ve müzik performans kaygısı durumları bazı değişkenlere göre incelenerek iyi oluş ile performans kaygısı arasındaki ilişki üzerinde durulmaktadır.

Uludağ Üniversitesi Fen-Edebiyat Fakültesi Sosyal Bilimler Dergisi Uludağ University Faculty of Arts and Sciences Journal of Social Sciences Cilt: 22 Sayl: 40 / Volume: 22 Issue: 40 
Söz konunu iliş̧inin tespiti için aşağıdaki sorulara cevap aranmaya çalışılmıştır;

1. Müzik öğretmeni adaylarının iyi oluş durumları ile müzik performans kaygıları cinsiyete göre farklılık göstermekte midir?

2. Müzik öğretmeni adaylarının iyi oluş durumları ile müzik performans kaygıları ögrenim yılına göre farklılık göstermekte midir?

3. Müzik öğretmeni adaylarının iyi oluş durumları ile performans kaygıları arasındaki ilişki nasıldır?

4. Müzik öğretmeni adaylarının iyi oluş alt boyut puanları ile performans kaygısı puanları arasında anlamlı bir ilişki var mıdır?

\section{Yöntem}

\section{Araştırma Modeli}

İyi oluş ile müzik performans kaygısını, cinsiyet ve öğrenim yılı değişkenlerine göre incelemek ve iyi oluş ile müzik performans kaygısı arasındaki ilişkiyi ortaya koymak amacıyla bu çalışmada genel tarama modellerinden ilişkisel tarama modeli kullanılmıştır. İlişkisel tarama modelleri "iki ve daha çok değişken arasındaki birlikte değişim varlığını veya derecesini belirlemeyi amaçlayan" araştırma modelleri (Karasar, 2006) olduğundan seçilen modelin araştırmanın yöntemine uygun olduğu düşünülmektedir.

\section{Örneklem}

Araştırmaya basit örnekleme yöntemi ile 2019-2020 öğretim yıll güz yarıyılında Bursa Uludağ Üniversitesi Eğitim Fakültesi Müzik Eğitimi Ana Bilim Dalında okuyan her sınıf düzeyinden (1, 2, 3, 4 ve 5. sınıf) seçilen $51 \mathrm{kız}$ ve 35 erkek olmak üzere toplam 86 öğrenci katılmıştır (Tablo 1).

Uludağ Üniversitesi Fen-Edebiyat Fakültesi Sosyal Bilimler Dergisi Uludağ University Faculty of Arts and Sciences Journal of Social Sciences Cilt: 22 Sayl: 40 / Volume: 22 Issue: 40 
Tablo 1: Örneklem

\begin{tabular}{lll}
\hline Cinsiyet & $\mathrm{f}$ & $\%$ \\
\cline { 2 - 3 } Kiz & 51 & 59.3 \\
Erkek & 35 & 40.7 \\
Toplam & 86 & 100 \\
& & \\
Sinıf & $\mathrm{f}$ & $\%$ \\
1 & 16 & 18.6 \\
2 & 22 & 25.6 \\
3 & 21 & 24.4 \\
4 & 21 & 24.4 \\
5 & 6 & 7.0 \\
Toplam & 86 & 100 \\
\hline
\end{tabular}

\section{Veri Toplama Araçları}

\section{Öğrenci Demografik Bilgi Formu}

Üniversite öğrencilerinin demografik özelliklerine ilişkin bilgiler araştırmacı tarafından geliştirilen "Öğrenci Demografik Bilgi Formu" ile toplanmıştır. Bilgi formunda, öğrencilerin cinsiyeti ve öğrenim yıllarına ilişkin sorulara yer verilmiştir.

\section{Perma İyi Oluş Ölçeği}

Seligman'ın (2011) iyi oluş ile ilgili beş boyutlu ( $\mathrm{P}=$ positive emotions $=$ olumlu duygular, $\mathrm{E}=$ engegament=bağlanma, $\mathrm{R}=$ positive relationships $=$ olumlu ilişkiler, $\quad \mathrm{M}=$ meaning=anlam ve $\mathrm{A}=$ accomplishment=başarılar) kuramını ölçüme dökmeyi amaçlayan ölçek Butler ve Kern, 2016 yılında tarafından geliştirilmiştir. Ölçek, Demirci vd. (2017) tarafından geçerlik ve güvenirliği yapılarak Türkçeye uyarlanmıştır. Demirci vd. (2017), orijinal formdaki 10’lu likert, 15 maddeli ve 5 alt boyutlu ölçme modeline uygun olarak Türkçe versiyonunu doğrulayıcı faktör analizi ile incelemişlerdir. 
Ölçeğin 5 alt boyutu aşağıdaki gibidir;

(P) Olumlu duygular: Neşe gibi olumlu duyguları yaşamak. Çevreyi olumlu bir şekilde algılamak.

(E) Bağlanma: Okul, organizasyon vb. için gerçekleştirilen faaliyetlerle zamanın nasıl

geçtiğini anlamayacak kadar bağlantı kurmak.

(R) Olumlu / iyi ilişkiler: Sosyal olarak bütünleşmiş olmak, başkaları tarafından destek ve değer görmek. Sosyal bağlantılarından memnun olmak olarak tanımlanabilir.

(M) Anlam: Hayatının değerli olduğuna inanmak.

(A) Başarı: Kendi belirlediği yaşam / iş hedeflerinde doğru ilerleme, günlük aktiviteleri yapabilme duygusu ve başarma duygusuna sahip olmak (Singh \& Raina, 2019).

Demirci vd. (2017) çalışmalarında ölçeğin faktör yüklerinin .42 ile .89 arasında değiştiği görülmüş ve beş boyutlu modelinin kabul edilebilir düzeyde uyum verdiği sonucuna ulaşılmıştır. Mevcut çalışmada da ölçekteki bu boyutları gösteren maddeler analizlere dâhil edilmiştir.

Demirci vd. (2017), çalışmalarında Cronbach alpha iç tutarlılık katsayısını ölçeğin toplam puanı için .91 , olumlu duygulanım alt boyutu için .81, bağlanma alt boyutu için .61, ilişkiler alt boyutu için .61, anlam alt boyutu için .77 , başarı alt boyutu için .70 olarak hesaplanmışken, mevcut çalışmada ise Cronbach alpha iç tutarlılık katsayısı ölçeğin toplam puanı için .93 , olumlu duygulanım alt boyutu için .86 , bağlanma alt boyutu için .70, ilişkiler alt boyutu için .66, anlam alt boyutu için .82 , başarı alt boyutu için .77 olarak hesaplanmıştır. 
Kenny Müzik Performans Kaygısı Envanteri (KMPKE)

Kenny Müzik Performans Kaygısı Envanterinin Türkçe uyarlaması 7'li likert tipinde 25 maddeden oluşmaktadır. Özevin Tokinan (2013) tarafından yapılan uyarlama çalışmasında maddelerin madde toplam korelasyonlarının .336 ile .651 arasında değiştiği bulunmuştur. Özevin Tokinan (2013) tarafindan yapılan çalışmada Cronbach Alpha iç tutarlık katsayısı .895 olarak bulunurken, mevcut çalışmada ise bu değer .94 olarak hesaplanmıştır.

\section{Verilerin Toplanması ve Çözümlenmesi}

Verilerin toplanmasında katılımcılara araştırmanın amacı konusunda bilgi verilmiş ve uygulamalar, okul ortamında öğrencilerin ders aralarında veya boş zamanlarında araştırmacı tarafından gerçekleştirilmiştir.

Toplanan verilerin normallik dağılımları yapılmış ve bunun sonucunda t-test ve Anova testlerinin kullanılması kararlaştırılmıştır. PERMA, KMPKE puanlarının cinsiyete göre ilişkisinin analizinde $\mathrm{t}$ testi, PERMA ve KMPKE puanlarının öğrenim yıllarına göre ilişkisinin analizinde ise ANOVA kullanılmıştır. PERMA ve KMPKE puanları arasındaki ilişki ile PERMA, MPK ve GANO arasındaki ilişkinin belirlenmesi için ise Pearson Korelasyon katsayısı hesaplanmıştır. Araştırmada örneklem ile ilgili veriler ise betimsel istatistikler kullanılarak frekans ve yüzdelik olarak hesaplanmıştır.

\section{Bulgular}

$\mathrm{Bu}$ bölümde müzik öğretmeni adaylarının iyi oluş ve müzik performans kaygılarının cinsiyet, öğrenim yılı değişkenlerine göre ilişkisine yönelik bulgular yer almaktadır. Aynı zamanda iyi oluş ve müzik performans kaygısı arasındaki ilişkiye ait bulgulara değinilmekte iyi oluşun tüm alt boyutlarının müzik performans kaygısı ile ilişkisi incelenmektedir. 
Tablo 2: KMPKE ve PERMA puanlama

PERMA

\begin{tabular}{llll}
\hline $\mathrm{M}$ & SD & Min & Max. \\
\hline 6.65 & 1.55 & 0.60 & 9.27 \\
3.30 & 1.06 & 1.32 & 5.64
\end{tabular}

KMPKE

Alınabilecek en düşük puanı 1, en yüksek puanı 10 olan Perma İyi Oluş Ölçeğini yanıtlayan müzik öğretmeni adaylarının puanları 0.60-9.27 arasında değişmekte olup, puan ortalamaları 6.65 olarak tespit edilmiştir. Alınabilecek en düşük puanı 0, en yüksek puanı 6 olan Kenny Müzik Performans Kaygısı Envanterini (KMPKE) yanıtlayan müzik öğretmeni adaylarının puanları ise 1.32-5.64 arasında değişmektedir. Kenny Müzik Performans Kaygısı Envanterini yanıtlayan müzik öğretmeni adaylarının puan ortalamaları ise 6.65 olarak tespit edilmiştir (Tablo 2).

Tablo 3: PERMA, KMPKE - cinsiyet

\begin{tabular}{lllllll}
\hline & Cinsiyet & M & SD & t & Df & P \\
\hline PERMA & K1z & 6.90 & 1.64 & 1.858 & 84 & 0.067 \\
& Erkek & 6.28 & 1.35 & & & \\
\multirow{2}{*}{ KMPKE } & Kiz & 3.32 & 1.11 & 0.202 & 84 & 0.840 \\
& Erkek & 3.27 & 1.00 & & & \\
\hline \multicolumn{2}{c}{$\mathrm{p}<0,05$} & & & & &
\end{tabular}

Tablo 3'te PERMA, KMPKE puanlarının cinsiyete göre değişimini gösterir t-testi analiz sonuçları görülmektedir. PERMA iyi oluş puanları cinsiyete göre değişmemektedir, $\mathrm{t}(84)=1.858, \mathrm{p}=0.067$. Aynı şekilde kızlar ve erkekler arasındaki müzik performans kaygıları farkı da anlamlı bulunmamıştır, $\mathrm{t}(84)=0.202, \mathrm{p}=0.840$. Ancak k1z öğrencilerin gerek iyi oluş gerekse müzik performans kaygısı ortalama puanlarının erkeklere kıyasla daha yüksek olduğu görülmektedir.

Uludağ Üniversitesi Fen-Edebiyat Fakültesi Sosyal Bilimler Dergisi Uludağ University Faculty of Arts and Sciences Journal of Social Sciences Cilt: 22 Sayl: 40 / Volume: 22 Issue: 40 
Tablo 4: PERMA, KMPKE - öğrenim y1lı

\begin{tabular}{lclllll}
\hline & $\begin{array}{c}\text { Öğrenim } \\
\text { Y11 }\end{array}$ & N & M & SD & F & P \\
\hline PERMA & 1 & 16 & 6.46 & 1.08 & 0.792 & 0.534 \\
& 2 & 22 & 6.74 & 1.24 & & \\
& 3 & 21 & 6.77 & 1.84 & & \\
& 4 & 21 & 6.87 & 1.69 & & \\
KMPKE & 5 & 6 & 5.68 & 2.09 & & 0.857 \\
& 1 & 16 & 3.54 & 1.21 & 0.330 & \\
& 2 & 22 & 3.16 & 1.02 & & \\
& 3 & 21 & 3.35 & 1.02 & & \\
& 4 & 21 & 3.24 & 0.94 & & \\
\hline
\end{tabular}

$\mathrm{p}<0,05$

Tablo 4'te PERMA ve KMPKE puanlarının öğrenim yıllına göre değişim durumuna ilişkin ANOVA tablosu görülmektedir. PERMA iyi oluş puanları öğrenim yılına göre değişmemektedir, $F(4,81)=0.792$, $p$ $=0.534$. Ancak ana bilim dalının 4. yılında eğitim alan müzik öğretmeni adayları en yüksek iyi oluş puanına sahip olurken, en düşük iyi oluş puanına 5. öğretim yılında eğitim alan öğrencilerin olduğu görülmektedir.

Aynı şekilde öğrenim yılının MPK üzerinde de anlamlı etkisi bulunamamaktadır, $F(4,81)=0.330, p=0.857$. Ancak yıllara göre MPK ortalamalarına bakıldığında 1. yıl öğrencilerin en yüksek MPK puanına sahip oldukları görülmektedir (Tablo 4).

Tablo 5: PERMA - KMPKE

\begin{tabular}{lll}
\hline & Pearson $\mathrm{r}$ & $\mathrm{P}$ \\
\cline { 2 - 3 } P-Olumlu Duygular & -0.400 & 0.001 \\
E-Bağlanma & -0.231 & 0.033 \\
R-Olumlu / İyi İlişkiler & -0.231 & 0.032 \\
M-Anlam & -0.364 & 0.001 \\
A-Başarı & -0.325 & 0.002 \\
PERMA-KMPKE GENEL & -0.369 & 0.001 \\
\hline
\end{tabular}
$\mathrm{p}<0,05$

Uludağ Üniversitesi Fen-Edebiyat Fakültesi Sosyal Bilimler Dergisi Uludağ University Faculty of Arts and Sciences Journal of Social Sciences Cilt: 22 Sayl: 40 / Volume: 22 Issue: 40 
Tablo 5'te PERMA ve KMPKE ilişkisini gösteren Pearson Korelasyon analizi yer almaktadır. PERMA'nın alt boyutları ile MPK arasındaki ilişkiye bakıldığında müzik performans kaygısının en az bağlanma ve olumlu/ iyi ilişkiler ile, en çok ise olumlu duygular boyutu ile olmak üzere tüm boyutlarla negatif yönde anlamlı korelasyona sahip olduğu görülmüştür.

PERMA genel puanı ile MPK arasında negatif yönlü ve anlamlı korelasyon bulunmuştur, $\mathrm{r}=-0.369, \mathrm{p}=0.001$ (Tablo 5).

\section{Tartışma ve Öneriler}

\section{Tartışma}

Araştırmada müzik öğretmeni adaylarının iyi oluşlarında cinsiyete göre anlamlı bir fark tespit edilememiş olmasına karşın kız öğrencilerin iyi oluş puan ortalamalarının erkek öğrencilere kıyasla daha yüksek olduğu görülmektedir. Cinsiyetler arasında bir farkın tespit edilememiş olması Müzik Eğitimi Ana Bilim Dalının her iki cinsiyet için sağladığı koşullardan kaynaklı olabileceği düşünülmektedir. Müzik Eğitimi Ana Bilim Dalında kadın veya erkek fark etmeksizin öğrenciler eşit haklar ve eşit imkânlardan faydalanmaktadırlar. Cinsiyet gözetmeksizin tüm müzik öğretmeni adayları benzer süreçlerden geçerek yetişmektedirler. $\mathrm{Bu}$ durum araştırmada müzik öğretmeni adaylarının iyi oluşlarında cinsiyete göre anlamlı bir fark elde edilememesini açıklayabilir. Ayrıca öğrencilerin Müzik Eğitimi Ana Bilim Dalına yetenek sınavı ile girdikleri unutulmamalıdır. Merkezi sınavlar ile yerleştirmenin aksine yetenek sınavı ile öğrenci alan bölümlere başvuru yapan öğrencilerin başvurdukları alanlar ilk tercihleri arasında yer almaktadır ve öğrenciler ilgi duydukları alanda eğitim almaktadırlar. Bu durumun müzik öğretmeni adaylarının ister kız isterse erkek olsun iyi oluşlarında etkili olduğu söylenebilir. Alan yazınında, mevcut araştırma sonucunu destekleyen ve değişik alanlarda da iyi oluşla cinsiyet arasında fark tespit edemeyen araştırmalara 
rastlanmaktadır (Dağ vd., 2019; Koç \& Keklik, 2020; Türköz \& Şahin Kıralp, 2019; Tuzgöl Dost, 2014). Erkekler lehine sonuç elde etmiş araştırmaların (Eryılmaz \& Ercan, 2011; Tümkaya, 2011) da tespit edilmiş olmasına karşın kadınların daha yüksek iyi oluş düzeylerinin olduğunu ortaya koyan araştırmalar da göze çarpmaktadır (Dilmaç \& Bozgeyikli, 2009; Gündoğdu \& Yavuzer, 2011; Nigar, 2014). Öztürk ve Siviş Çetinkaya, (2015: 340) iyi oluş konusunda cinsiyete özgü tutarlı bir farklılaşmanın bulunmadığı, bazı araştırma bulgularında kadın ve erkeklerin iyi oluş düzeylerinde cinsiyete özgü bir farklılaşmanın bulunması durumunda dahi, bu durumun çok küçük bir farklılığ 1 tanımladığı yönünde görüş bildirmişlerdir.

Müzik öğretmeni adaylarının müzik performans kaygılarında da cinsiyete dayalı anlamlı bir fark bulunamamıştır. Ancak kız müzik öğretmeni adaylarının müzik performans kaygısı ortalama puanlarının erkeklerin ortalamalarından daha yüksek olduğu görülmektedir. Müzik Eğitimi Ana Bilim Dalları müzik öğretmeni yetiştiren kurumlar olduğundan, öğrenciler çalgı dersleri dâhil tüm alan dersleri yanı sıra öğretim programında yer alan birçok öğretmenlik meslek bilgisi dersinden de başarılı olmak zorundadırlar. Teorik dersleri çalışmak öğrencilerin çalgı çalışmak için ayırdıkları zamanı azaltmaktadır. $\mathrm{Bu}$ nedenle yıl içerisinde sahne deneyimlerinin sıklığı her iki cinsiyet için de azalmaktadır. Her iki cinsiyet için sahne deneyimi olanakları, çalgı çalışma ortamları eşit oranda sunulmaktadır. Bu durum, müzik öğretmeni adaylarının müzik performans kaygılarında cinsiyete göre anlamlı bir fark bulunamamış olmasının nedeni olarak açıklanabilir. Literatürde k1z öğrencilerin müzik performans kaygılarının erkek öğrencilere kıyasla daha yüksek olduğunu ortaya koyan araştırmalara rastlanırken (Abel \& Larkin, 1990; Aydın \& İşgörür, 2018; Baydağ ve Alpagut, 2016; Çırakoğlu, 2013; Jelen, 2010; Özevin Tokinan, 2014; Rae \& McCambridge, 2004; Studer vd., 2011; Topoğlu, 2014; Yöndem, 2007) mevcut araştırmada olduğu gibi cinsiyetler arasında müzik 
performans kaygılarında anlamlı fark tespit edilemeyen araştırmalara da rastlanmaktadır (Çevik Kılıç, 2018; Deniz, 1998; Küçük, 2010; Onuray Eğilmez, 2015; van Kemenade vd., 1995).

Araştırmada müzik öğretmeni adaylarının iyi oluşlarında öğrenim yılına göre anlamlı fark elde edilememiştir. Ancak Müzik Eğitimi Ana Bilim Dalının 4. yılında eğitim alan müzik öğretmeni adaylarının en yüksek iyi oluş puan ortalamalarına sahip oldukları, en düşük iyi oluş puan ortalamasına ise 5. öğretim yılında eğitim alan öğrencilerin sahip olduğu görülmektedir. Bu çalışmanın yürütüldüğü örneklem grubunun özellikleri göz önüne alındığında; 4 yıllık lisans programının 4. yılında gerek aldıkları eğitim sürecinde kendilerine belirledikleri hedefe yani mezuniyete yaklaşmış olmaları gerekse öğretmenlik uygulaması gibi meslek dersleri ile kendilerini öğretmenlik mesleğine yakınlaşmış hissetmeleri öğrencilerin iyi oluş düzeylerinin artmasında etkili olduğu söylenebilir. Öte yandan normal öğrenim süresinde mezun olamayıp öğrenim süresi 5. yıla uzayan öğrencilerin en düşük iyi oluş puan ortalamalarına sahip oldukları görülmektedir. $\mathrm{Bu}$ durumunun nedeni, öğrencilerin birlikte eğitim aldıkları sınıf arkadaşlarının mezun olmasıyla kendilerini yalnız hissediyor olmaları ve yılın uzamasından dolayı başarısızlık duygusunu yaşıyor olmaları olarak açıklanabilir.

Öğretim yılı arttıkça müzik öğretmeni adaylarının daha çok sahneye çıkma imkânları olduğu bilinmektedir. Sahnede yer alma sıklığının performans kaygısını azaltacağı varsayılmaktadır ancak öğrencilerin müzik performans kaygılarında da öğrenim yılı arttıkça bir farkın oluşmadığı görülmektedir. Yıllar arttıkça deneyim kazandığı düşünülen öğrencilerin performans kaygılarında anlamlı bir değişiklik görülmemektedir. Ancak yıllara göre MPK ortalamalarına bakıldığında 1. yıl öğrencilerin en yüksek MPK puanına sahip oldukları göze çarpmaktadır. $\mathrm{Bu}$ durum, birinci sınıf öğrencilerinin performans sınavlarında ilk kez komisyon tarafından değerlendiriliyor olmalarından 
ötürü olabileceği düşünülmektedir. Ancak Jelen (2010: 3389), araştırmasında birinci sınıf öğrencilerinin müzik performans kaygılarının ikinci ve dördüncü sınıf öğrencilerine göre daha düşük olduğunu tespit etmiştir. Kılıç (2018) araştırmasında son sınıf öğrencilerinin sınav performans kaygısı düzeylerinin önemli ölçüde yüksek olduğunu, birinci sınıf öğrencilerin ise daha düşük kayg1 düzeylerine sahip olduğunu belirtmektedir. Mevcut araştırma bulgusuna göre müzik öğretmeni adaylarının sınıf düzeyine göre MPK'larında anlamlı bir fark tespit edilememiş olmasıyla, örneklem grubunda yer alan müzik öğretmeni adaylarını sanatsal deneyimlerinin performans kaygılarını azaltan bir unsur olmadığ 1 söylenebilir. Nitekim Sadler ve Miller (2010) ile Özevin Tokinan (2014) araştırmalarında daha uzun süre resmi eğitim görmenin performans kaygısı üzerinde önemli bir etkisinin olmadığı sonucunu paylaşmışlardır. Öğretim yılının performans kaygısı üzerinde etkili olmadığını ortaya koyan söz konusu araştırmalara rağmen alan yazınında sınıf düzeyi arttıkça müzik performans kaygı puan ortalamalarının arttığını ortaya koyan araştırmalar da göze çarpmaktadır (Onuray Eğilmez, 2015).

Araştırmada müzik öğretmeni adaylarının iyi oluşları ile müzik performans kaygılarında negatif yönlü ve anlamlı korelasyon bulunmuştur. Görülmektedir ki kendilerini iyi hisseden müzik öğretmen adaylarının performans anındaki kaygıları da azalmaktadır. Ayrıca iyi oluşun alt boyutları ile müzik performans kaygıları arasındaki ilişkiye bakıldığında ise neşe gibi olumlu duyguları yaşayan, çevreyi olumlu bir şekilde algılayan, yaptığı işle zamanın nasıl geçtiğini anlamayacak kadar bağlantı kuran, başkaları tarafından destek ve değer gören, hayatının değerli olduğuna inanan ve kendi belirlediği yaşam / iş hedeflerinde bir başarı hissi yaşayan müzik öğretmeni adaylarının performans sırasında hissettikleri kaygılarının da azaldığı görülmüştür.

Araştırmada tüm alt boyutlar arasında MPK'nın en az bağlanma ve olumlu / iyi ilişkiler ile, en çok ise olumlu duygular alt boyutu ile 
negatif yönde anlamlı korelasyona sahip olduğu tespit edilmiştir. Sosyal varlık olan insanlar için sevilmek ve başkaları tarafindan destek, değer görmek önemlidir. Bu nedenle sosyal ilişkiler önem arz etmektedir (Forgeard vd., 2011 86). Butler ve Kern'e (2016: 3) göre sosyal ilişkiler bireylerin iyi oluşlarının özünü oluşturmakta, Tay ve diğerlerine (2012) göre ise sosyal destek depresyonu azaltmaktadır ancak müzik performans kaygısı göz önünde bulunduğunda mevcut araştırmada kaygının en az olumlu / iyi ilişkiler boyutu ile negatif yönlü ilişkili olduğu görülmektedir. Diğer bir değişle müzik öğretmeni adaylarının çevreleri ile sahip oldukları olumlu ilişkileri performans kaygılarını diğer alt boyutlara kıyasla daha düşük oranda azaltmaktadır.

MPK'nın, iyi oluşun diğer alt boyutları ile ilişkisi ele alındığında, bağlanma alt boyutunun da müzik öğretmeni adaylarının MPK'ları ile en az ilişkili olduğu görülmektedir. Yaptığı işe zamanın nasıl geçtiğini anlamayacak kadar bağlanan bireylerin, net hedefleri olduğu, yaptıkları iş ile içten ilgilendiği belirtilmektedir (Forgeard vd., 2011: 84). Ancak MPK göz önünde bulundurulduğunda, müzik öğretmeni adaylarının yaptığı işe bağlanma durumlarının müzik performans kaygılarına diğer alt boyutlara kıyasla daha az etki ettiği söylenebilir.

İyi oluş alt boyutlarından olumlu duygular alt boyutunun müzik performans kaygısı ile en çok ilişkili olan alt boyut olduğu görülmektedir. Seligman'a (2011) göre yaşamlarımızda iyi yaşamak için olumlu bir duyguya ihtiyacımız bulunmaktadır. Bağlılık, mutluluk, umut, sevgi ve huzur gibi olumlu duygular, enerjimizi yenileyerek bizi gençleştirmektedir. Mevcut araştırma sonucunda da neşe vb. olumlu duyguları yaşamanın ve çevreyi olumlu bir şekilde algılamanın müzik performans kaygısını azaltmada daha etkili olduğu tespit edilmiştir. Öztürk ve Siviş Çetinkaya (2015) araştırmalarında bölümünü severek ve isteyerek tercih eden katılımciların olumlu duygu puanlarının bölümünü severek ve isteyerek tercih etmeyen katılımcıların olumlu 
duygu puanlarından anlamlı biçimde yüksek olduğu tespit edilmiştir. Müzik öğretmeni adaylarının okumak istedikleri alanda eğitim almak üzere yetenek sınavıyla Müzik Eğitimi Ana Bilim Dalına girmiş oldukları varsayılırsa, bu durumun müzik öğretmeni adaylarının olumlu duygularının yüksek olabileceğini ve müzik performans kaygısını olumlu yönde etkileyebileceğini düşündürmektedir.

\section{Öneriler}

Araştırma sonuçları kendini iyi hissetmenin müzik öğretmeni adaylarının sahnede yaşadıkları kaygıyı azalttığını ancak müzik öğretmeni adaylarının iyi oluşlarının öğretim yılıyla ilişkili olmadığını ortaya koymaktadır. Bu noktada müzik öğretmeni adaylarının sahne performanslarını etkileyebilecek kaygının azaltılmasında etkili olduğu belirlenen iyi oluşun farklı değişkenlerle olan ilişkisinin ortaya konulması gerekmekte, bu yönde yapılacak ileri araştırmalara ihtiyaç duyulmaktadır. Ayrıca müzik performans kaygısının da ilişkili olabileceği düşünülen diğer değişkenler ile ilişkisi araştırılmalı ve meslek hayatları boyunca topluluk önünde performans sergilemek zorunda olacak olan müzik öğretmeni adaylarının problem olarak algılanan performans kaygılarının azaltılmasına yönelik girişimlerde bulunulmalıdır. Müzik öğretmeni adaylarının çalgılarını daha çok çalışmalarına olanak sağlamak üzere müfredatta düzenlemeler yapılması, öğrencilere daha sı sahneye çıkabilme olanakları sağlanması, müzik performans kaygısı ile baş edebilme yöntemlerine yönelik bilgilendirme ve uygulamaların yapılması performans sırasında hissedilen kaygının azaltılmasında etkili olacaktır. Böylece müzik performans kaygıları ile negatif yönlü anlamlı ilişkisi tespit edilen müzik öğretmeni adaylarının iyi oluş düzeylerinde de artış görülecektir.

Araştırma bulguları, olumlu duyguları yüksek, sosyal ilişkileri iyi, yaptığı işe yüksek düzeyde bağlanabilen, hayatın anlamlı olduğuna inanan, başarılı müzik öğretmeni adaylarının müzik performans 
kaygılarının düşük olacağını göstermektedir. Bu noktada müzik öğretmeni adaylarının bahsi geçen özellikler ile donanımlı yetişmelerinde Müzik Eğitimi Ana Bilim Dalları tarafından gerekli ortamların sağlanması ve mevcut derslerin işleniş basamaklarında öğrencilerin olumlu ilişkiler, olumlu duygular vb. iyi oluşlarını yükseltecek etkinliklere yer verilmesi önerilmektedir. Müzik öğretmeni adaylarının olumlu duyguları ve sosyal ilişkilerini güçlü tutmak için koro, orkestra vb. grup çalışmalarından yararlanılabilir, mevcut derslerde grup çalışmalarına yer verilebilir. Ayrıca Topluma Hizmet Uygulamaları derslerinde geliştirilecek projelerin de yine müzik öğretmeni adaylarının iyi oluşlarına katkı sunacak projeler olmasına özen gösterilmelidir.

\section{Bilgi Notu}

Makale araştırma ve yayın etiğine uygun olarak hazırlanmıştır. $\mathrm{Bu}$ çalışma için gerekli etik kurulu izni, Bursa Uludağ Üniversitesi Sosyal ve Beşeri Bilimler Araştırma ve Yayın Etik Kurulunun 3 Haziran 2020 tarihinde gerçekleştirdiği 2020-03 sayılı oturumda alınmıştır.

\section{Kaynakça}

Abel, J. \& Larkin, T. K. (1990). Anticipation of performance among musicians: physiological arousal, confidence, and state-anxiety. Psychology of Music, 18(2), 171-182.

Ateş, B. (2016). Üniversite öğrencilerinde akademik başarının yordayıcısı olarak psikolojik iyi oluş ve sosyal yetkinlik. Elektronik Sosyal Bilimler Dergisi, 15(59), 1203-1214.

Aydın, B. \& İşgörür, Ü. (2018). Ortaokul ve lise düzeyinde öğrenim gören konservatuvar öğrencilerinin müzik performans kaygılarının çeşitli değişkenlere göre incelenmesi. Afyon Kocatepe Üniversitesi Akademik Müzik Araştırmaları Dergisi, (7), 1-20. 
Baydağ, C. \& Alpagut, U. (2016). Müzik eğitimi bölümü ve konservatuvar öğrencilerinin sahne / performans kaygısı açısından karşılaştırılması (pilot çalışma). Uluslararası Sosyal Araştırmalar Dergisi, 9(44), 857-864.

Baydağ, C. \& Bolat Başoğlu, M. (2018). Müzik eğitimi perspektifinde performans kaygısına genel bir bakış. Journal of Social and Humanities Sciences Research, 5(25), 2204-2212.

Brotons, M. (1994). Effects of performing conditions on music performance anxiety and performance quality. Journal of Music Therapy, 31(1), 63-81.

Butler, J. \& Kern, L. M. (2016). The PERMA-profiler: a brief multidimensional measure of flourishing. International Journal of Wellbeing, 6(3), 1-48.

Cemali, M. (2017). Müzik bölümü lisans ögrrencilerinde performans kaygısına neden olan faktörlerin belirlenmesi. (Yayımlanmamış yüksek lisans tezi). Ankara: Hacettepe Üniversitesi Sağlık Bilimleri Enstitüsü.

Çevik Kılıç, D. B. (2018). An investigation of music teacher candidates' performance anxiety levels in piano examinations. Journal of Education and Learning, 7(1), 299-308.

Çırakoğlu, O. C. (2013). Sahnedeki düşman: müzisyenlerde performans kaygısı üzerine bir gözden geçirme. Başkent Üniversitesi Türk Psikoloji Yazllart, 16(32), 95-104.

Çimen, G. (2001). Konser kaygısı. G.Ü. Gazi Eğitim Fakültesi Dergisi, 21(2), 125-133.

Dağ, A., Korkutata, A., Özavc1, R. (2019). Sportif etkinlik işletmelerinde çalışan personelin öznel iyi oluş düzeyleri ile yaşam doyumlarının bazı değişkenler açısından incelenmesi. Uluslararası Spor Egzersiz \& Antrenman Bilimi Dergisi, 5(3), 154-162. 
Dempsey, E. \& Comeau, G. (2019). Music performance anxiety and self-efficacy in young musicians: effects of gender and age. Music Performance Research, 9, 60-79.

Demirci, İ, Ekşi, H., Dinçer, D., Kardaş, S. (2017). Beş boyutlu iyi oluş modeli: Perma ölçeği Türkçe formunun geçerlik ve güvenirliği. The Journal of Happiness \& Well-Being, 5(1), 60-77.

Deniz, J. (1998). Mesleki müzik eğitimi öğrencilerinin konser kaygılarının cinsiyet, kişilik ve okul değişkenleri açısından incelenmesi. Marmara Üniversitesi Atatürk Ĕ̈itim Fakültesi Ĕgitim Bilimleri Dergisi, 10(10), 75-82.

Dilmaç, B. \& Bozgeyikli, H. (2009). Öğretmen adaylarının öznel iyi olma ve karar verme stillerinin incelenmesi. Erzincan Eğitim Fakültesi Dergisi, 11(1), 171-187.

D'raven, L. L. \& Pasha-Zaidi, N. (2016). Using the PERMA model in the United Arab Emirates. Social Indicators Research, 125(3), 905-933.

Dobos, B., Piko, B. F., Kenny, D. T. (2019). Music performance anxiety and its relationship with social phobia and dimensions of perfectionism. Research Studies in Music Education, 41(3), 310-326.

Erdoğan, F. (2020, Nisan 25). İyi oluş nedir?.

https://fatierdogan.com/psikolojik-iyi-olus.

Eryılmaz, A. \& Ercan, L. (2011). Öznel iyi oluşun cinsiyet, yaş grupları ve kişilik özellikleri açısından incelenmesi. Türk Psikolojik Danışma ve Rehberlik Dergisi, 4(36), 139-151.

Fehm, L. \& Schmidt, K. (2006). Performance anxiety in gifted adolescent musicians. Journal of Anxiety Disorders, 20(1), 98-109.

Forgeard, M. J. C., Jayawickreme, E., Kern, M., Seligman, M. E. P. (2011). Doing the right thing: measuring well-being for public policy. International Journal of Wellbeing, 1(1), 79-106. 
Gidergi Alptekin, A. (2012). Müzik performans anksiyetesi. Trakya Üniversitesi Sosyal Bilimler Dergisi, 14(1), 137-148.

Girgin, D. (2017). The relations among musical instrument performance self-efficacy, self-esteem and music performance anxiety in pre-service music teachers. Educational Research and Review, 12(11), 611-616.

Gündoğdu, R. \& Yavuzer, Y. (2011). Eğitim fakültesi öğrencilerinin öznel iyi oluş düzeyleri ve psikolojik ihtiyaçlarının incelenmesi. Mehmet Akif Ersoy Üniversitesi Eğitim Fakültesi Dergisi, 12(23), 115131.

Jelen, B. (2010). Müzik öğretmeni adaylarının müzik performans kaygıs1 ve piyano performans öz yeterlik düzeylerinin incelenmesi. Ídil Sanat Dergisi, 6(39), 3389-3414.

Kenny, T. D. \& Osborne, S. M. (2006). Music performance anxiety: new insights from young musicians volume. Advances in Cognitive Psychology, 2(2-3), 103-11.

Kabakçı, C. (2016). Sahne performansı kaygısında farkındalık ve mücadele. Sahne ve Müzik Eğitim-Araştırma e-Dergisi, (3), 86-96.

Kafadar, A. (2009). Piyanistler örneğinde müzisyenlere özgü performans anksiyetesi. (Yayımlanmamış yüksek lisans tezi). İzmir: Dokuz Eylül Üniversitesi Güzel Sanatlar Enstitüsü.

Karakulak Özkan, K. (2020, Nisan 27). Kayg1 (anksiyete). http://www.sokrates-psikiyatri.com.tr/index.php/makaleler/detay/18.

Karasar, N. (2006). Bilimsel araştırma yöntemi. Nobel Yayın Dağıtım.

Koç, M. \& Keklik, İ. (2020). Hacettepe Üniversitesi'nde çalışan araştırma görevlilerinin psikolojik iyi oluş düzeylerinin yordanması. Hacettepe Üniversitesi Eğitim Fakültesi Dergisi, 35(1), 107-119.

Köknel, Ö. (1982). Kaygıdan mutluluğa kişilik. Altın Kitaplar Matbaası. 
Myers, J. E., Sweeney, T. J., Witmer, J. M. (2000). The wheel of wellness counseling for wellness: a holistic model for treatment planning. Journal of Counseling \& Development, 78, 251-266.

Nigar, F. (2014). Ortaokul öğrencileri ile yatılı bölge ortaokul ögrencilerinin öznel iyi oluş ve temel psikolojik ihtiyaçlar düzeyinin karşılaştırması. (Yayımlanmamış yüksek lisans tezi). Tokat: Gaziosmanpaşa Üniversitesi Eğitim Bilimleri Enstitüsü.

Onuray Eğilmez, H. (2015). Pre-service music teachers' piano performance self-efficacy belief inversely related to musical performance anxiety levels. Educational Research and Reviews, 10(18), 2558-2567.

Özevin Tokinan, B. (2013). Kenny müzik performans kaygıs1 envanterini Türkçe'ye uyarlama çalışması. Ahi Evran Üniversitesi Kırşehir Ĕgitim Fakültesi Dergisi (KEFAD), 14(1), 53-65.

Özevin Tokinan, B. (2014). Öğretmen adaylarının müzik performans kaygılarının bireysel özellikler bakımından incelenmesi. NWSA-Fine Arts, 9(2), 84-100.

Özgür, C. (2017). Sahne performansında dikkat kaybı, stres ve kaygıya yönelik psikolojik yöntemler. Konservatoryum, 4(1), 21-41.

Öztürk, A. \& Siviş Çetinkaya, R. (2015). Eğitim fakültesi öğrencilerinin öznel iyi oluş düzeyleri ile tinsellik, iyimserlik, kaygı ve olumsuz duygu düzeyleri arasındaki ilişki. Marmara Üniversitesi Atatürk Ĕgitim Fakültesi Eğitim Bilimleri Dergisi, 42(42), 335-356.

Perma (2020, Nisan 26). Perma theory of well-being and Perma workshops.

https://ppc.sas.upenn.edu/learn-more/perma-theory-well-being-andperma-workshops. 
Piji Küçük, D. (2010). Müzik öğretmeni adaylarının sınav kaygısı, benlik saygısı ve çalgı başarıları arasındaki ilişkinin incelenmesi. Ahi Evran Üniversitesi Kırşehir Eğitim Fakültesi Dergisi, 11(3), 37-50.

Rae, G. \& McCambridge, K. (2004). Correlates of performance anxiety in practical music exams. Psychology of Music, 32(4), 432-439.

Sadler, M. \& Miller, J. C. (2010). Performance anxiety: a longitudinal study of the roles of personality and experience in musicians. Social Psychological and Personality Science, 1(3), 280-287.

Seligman, E. P. M. (2011). Flourish: a visionary new understanding of happiness and well-being. Free Press.

Studer, R., Danuser, B., Hildebrandt, H., Arial, M., Gomez, P. (2011). Hyperventilation complaints in musical performance anxiety among classical music students. Journal of Psychosomatic Research, 70(6), 557-564.

Tamborrino, R. A. (2001). An examination of performance anxiety associated with solo performance of college-level music majors. Dissertation Abstracts International Section A: Humanities and Social Sciences, 62(5-A), 1636.

Tay, L. Tan, K., Diener, E., Gonzalez, E. (2012). Social relations, health behaviors, and health outcomes: a survey and synthesis. Applied Psychology: Health and Well-being, 5(1), 28-78.

Teztel, G. \& Aşkın, C. (2007). Sahne heyecanının Türk müzisyenler arasındaki yaygınlığı ve çözüm yöntemleri. İtüdergisi / B Sosyal Bilimler, 4(2), 3-10.

Topoğlu, O. (2014). Musical performance anxiety: relations between personal features and state anxiety levels of pre-service music teachers. International Online Journal of Educational Sciences, 6(2), 337-348. 
Tuzgöl Dost, M. (2004). Üniversite ögrencilerinin öznel iyi oluş düzeyleri. (Yayımlanmamış doktora tezi). Ankara: Hacettepe Üniversitesitesi Sosyal Bilimler Enstitüsü.

Tümkaya, S. (2011). Humor styles and socio-demographic variables as predictors of subjective well-being of Turkish university students. Education and Science, 36(160), 158-170.

Türköz, S. \& Şahin Kıralp, F. S. (2019). Öğretmen adaylarının öznel iyi oluş, algılanan sosyal destek ve kendini saklama düzeylerinin incelenmesi. Ondokuz Mayls Üniversitesi Eüitim Fakültesi Dergisi, 38(2), 51-66.

van Kemenade J. F., van Son M. J., van Heesch N. C. (1995). Performance anxiety among professional musicians in symphonic orchestras: a self-report study. Psychological Reports, 77(2), 555-562.

Yağışan, N. (2009). A survey of music performance anxiety among Turkish music students. Turkish Journal of Music Education, 2(1), 211.

Yöndem, Z. D. (2007). Performance anxiety, dysfunctional attitutes and gender in university music students. Social Behavior and Personality An International Journal, 35(10), 1415-1426.

Uludağ Üniversitesi Fen-Edebiyat Fakültesi Sosyal Bilimler Dergisi Uludağ University Faculty of Arts and Sciences Journal of Social Sciences Cilt: 22 Sayl: 40 / Volume: 22 Issue: 40 


\section{EXTENDED ABSTRACT}

It is believed that for a good musical performance, firstly the musician should feel well. This "feeling well" is called "well-being" in positive psychology and takes its place in the literature as a concept about how he/she sees the situation in his/her life. In the multidimensional well-being model that Seligman has developed by combining different components, five ways are suggested for individuals to reach happiness. Seligman (2011, from D'raven \& Pasha-Zaidi, 2016) emphasizes that the first way to be happy is to maximize the "positive emotions" for the enjoyable life. The second way is "engaging to life", which can be defined as being immersed in an event that cannot understand how time passes. Third way is "meaningful life" that is about the purpose and meaning, giving the feeling that life is valuable and worth living. Fourth way can be achieved with "positive relationships" that results in being loved and valued by others and the fifth way can be achieved through "accomplishment", which is believed to bring self-efficacy.

Considering the model suggested by Seligman, the idea prevailed that wellbeing might have a positive relationship with music performance. In line with the said idea, it was assumed that there may be a relationship between well-being and music performance anxiety. The research, shaped by this assumption and was conducted to give an idea of whether music teacher candidates' well-being have an effect on the level of anxiety they may encounter during performance. For this purpose, the wellbeing and musical performance anxiety states of the pre-service music teachers were analysed according to gender and education year variables, and the relationship between well-being and performance anxiety was determined. The effects of subdimensions of well-being, having positive emotions, attachment to life, sustaining life by means of life, having positive relationships, and success on performance anxiety were determined one by one.

In the research that correlational survey model has been used, the opinions of 86 students (51 girls and 35 boys), who were selected from each grade level (1, 2, 3, 4 and 5 grade) from Music Education Department, Bursa Uludă̆ University Faculty of Education, were asked. The data were collected with the Student Demographic Information Form, Perma Wellbeing Scale and the Kenny Music Performance Anxiety Inventory (KMPAI). To analyse the relationship between PERMA and KMPAI scores by gender, $t$-test was used. ANOVA was used to analyse the relationship between PERMA and KMPAI scores according to the education years. Pearson Correlation Coefficient was calculated to determine the relationship between PERMA and KMPAI scores.

Uludağ Üniversitesi Fen-Edebiyat Fakültesi Sosyal Bilimler Dergisi Uludağ University Faculty of Arts and Sciences Journal of Social Sciences Cilt: 22 Sayl: 40 / Volume: 22 Issue: 40 
There was no significant difference in the well-being and music performance anxiety of music teacher candidates according to gender and education year. Music performance anxiety was found to have a negative correlation in all sub-dimensions, with the least attachment and positive relationships in the sub-dimension and the most positive emotions sub-dimension. In addition, a negative and significant correlation was found between the PERMA general score and the MPK general score.

While there are studies in the literature that address the causes of performance anxiety and methods of dealing with anxiety, studies that reveal the relationship between well-being and performance anxiety have not been sufficiently encountered. The research is considered important in terms of giving an idea about the effect of the well-being of musicians on performance anxiety. In addition, it increases the importance of research in terms of being one of the few studies that reveal this relationship.

Research results reveal that feeling well reduces the anxiety experienced by pre-service music teachers on stage. Based on the results of the research, it is seen that the well-being of pre-service music teachers is not related to duration of education. At this point, the relationship between well-being, which is determined to be effective in reducing performance anxiety that may affect the stage performances of pre-service music teachers, should be revealed with different variables, and in this direction, further research is needed.

In addition, the relationship between other variables that are thought to be related to music performance anxiety should be investigated and solution suggestions should be brought for the performance anxiety perceived as a problem for pre-service music teachers who will have to perform in front of the community throughout their teaching profession. 